\section{$\underset{\substack{\text { hommes } \\ \text { \& migrations }}}{ }$}

\section{Hommes \& migrations}

Revue française de référence sur les dynamiques

migratoires

1307 | 2014

L'Afrique qualifiée dans la mondialisation

\title{
Le Studio Arax
}

\section{Marie Caquel}

\section{(QpenEdition \\ Journals}

\section{Édition électronique}

URL : http://journals.openedition.org/hommesmigrations/2910

DOI : 10.4000/hommesmigrations.2910

ISSN : 2262-3353

\section{Éditeur}

Musée national de l'histoire de l'immigration

\section{Édition imprimée}

Date de publication : 1 juillet 2014

Pagination : 162-165

ISBN : 978-2-919040-28-5

ISSN : $1142-852 X$

\section{Référence électronique}

Marie Caquel, «Le Studio Arax », Hommes \& migrations [En ligne], 1307 | 2014, mis en ligne le 15 janvier 2015, consulté le 22 septembre 2020. URL : http://journals.openedition.org/hommesmigrations/2910 ; DOI : https://doi.org/10.4000/hommesmigrations.2910 


\section{COLLECTION}

\section{LE STUDIO ARAX}

MARIE CAQUEL, doctorante en histoire culturelle, université de Lorraine, CERCLE. Chargée de mission au Musée de l'histoire de l'immigration sur la refonte de l'exposition permanente Repères.

$\mathrm{E}_{\mathrm{t}}^{\mathrm{n}}$ 2009, le Musée de l'histoire de l'immigration acquiert un fonds de 227 plaques de verre, œuvre du photographe Krikor Djololian Arax'. À l'occasion de la réouverture de l'exposition permanente du Musée en juillet 2014 après deux mois de travaux, 6 tirages photographiques d'après la numérisation des plaques de verre font partie du nouvel accrochage. C'est l'occasion de mettre en valeur un fonds, dont l'auteur, bien connu de la communauté arménienne de France, mais aussi plus généralement du monde artistique, sportif et politique de son époque, mérite d'être redécouvert.

Krikor Djololian naît à Adabazar en Turquie, en 1897. Très vite, sa mère l'emmène avec ses deux frères à Constantinople (actuel Istanbul), où il fait ses études. Les trois frères auront des destins différents mais tous profondément marqués par les atrocités du génocide arménien. Durant la Première Guerre mondiale, les défaites du gouvernement ottoman et le puissant mouvement nationaliste turc exacerbent les ressentiments anti-arméniens. Dès 1915, le gouvernement ottoman procède au désarmement puis à l'exécution de tous les soldats arméniens au sein de l'armée ottomane. Alors qu'il était soldat dans l'armée ottomane, Haïg, frère de Krikor, est assassiné. Hagop, son autre frère, journaliste et écrivain, parvient à échapper à la rafle du 24 avril 1915, au cours de laquelle 650 intellectuels et notables arméniens de Constantinople sont arrêtés, déportés puis massacrés pour la plupart. II reste caché deux ans et part en 1920 pour la Roumanie, où il devient un professeur renomméz. Quant à Krikor, il est arrêté et déporté. Son parcours jusqu'au début des années 1920 reste peu connu, Krikor étant resté silencieux sur cet épisode douloureux de sa vie. Il parvient néanmoins à revenir à Constantinople et y reste jusqu'en 1922. À la veille du traité de Lausanne de 1923, il émigre avec sa mère en France, à l'instar de nombreux réfugiés arméniens. Arrivé par bateau à Marseille, il rejoint Paris où il reprend les activités qu'il a laissées : le sport et la photographie.

Déjà à Constantinople, Krikor s'intéresse au sport et au scoutisme, activités très développées dans la communauté arménienne de par les valeurs dont elles sont porteuses. Comme pour beaucoup de nations sans État, le sport est un vecteur identitaire et un facteur de cohésion "nationale" important ${ }^{3}$. Les Arméniens organisent même leurs propres Jeux olympiques en 1911 dans le stade du Club Union de Constantinople. Ainsi, l'organisation de scoutisme des Ho-Men-Et-Men (HMEM)4, dont la devise signifie "Élève-toi pour élever les autres", est créée à Constantinople en 1918 et continuera ses activités en exil. Dans ce cadre, Krikor dirige une troupe de plusieurs cen-

1. Je remercie vivement Patrice Djololian pour son témoignage. 2. Il est déporté dix ans en Sibérie lors de l'arrivée des communistes en Roumanie. Il décède à Bucarest en 1973. Il est admis à l'Académie nationale de Roumanie à titre posthume en 2013. 3. Nicolas Palluau, “Entre nation et religion. Scoutisme et organisation des jeunes immigrés (1920-1950)", in Cahiers de la Méditerranée, $n^{\circ} 78,2009$ [en ligne] 4. Ou Union générale arménienne d'éducation physique et de scoutisme (UGA). 
taines de scouts : il reçoit, en 1921, une lettre de lord Baden Powell, baron, militaire britannique et fondateur du scoutisme, le remerciant de lui avoir envoyé des photographies de sa troupe de scouts et le félicitant pour leur apparente intelligence. En dehors du scoutisme, sa passion pour le sport le mène à organiser des compétitions sportives, notamment d'athlétisme, dans l'Empire puis à Paris.

\section{Le retour à la photographie}

En France, il reprend également ses activités de photographe qu'il avait entamées au pays. Son activité de journaliste le mène à créer, à la fin des

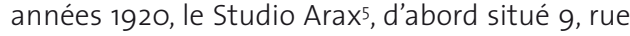
Papillon dans le IX arrondissement de Paris. II s'établira définitivement au 31 boulevard Raspail, dans le VII arrondissement au début des années 1930.

Tout au long de sa carrière, il photographie des sujets très variés. C'est ainsi que le Musée de I'histoire de l'immigration acquiert un reportage de 43 planches sur l'Exposition coloniale de 1931. Cette thématique est à mettre en relation avec le passé du Palais de la Porte Dorée, qui abrite depuis 2007 le Musée de l'histoire de l'immigration. À l'origine, le Palais avait été construit dans le cadre de l'Exposition coloniale de 1931. II a accueilli successivement le Musée permanent des colonies, puis le Musée de la France d'outre- 


\section{COLLECTION}

mer et le Musée d'art d'Afrique et d'Océanie (MAAO) jusqu'en 2003.

Les plaques de verre représentent notamment les pavillons de l'Exposition coloniale : on y découvre des vues générales de l'exposition, le pavillon de l'Annam', la reconstitution du temple d'Angkor, le pavillon algérien, celui de Madagascar, plusieurs clichés du zoo où les visiteurs pouvaient voir des animaux exotiques et le Musée des colonies. Arax ne sait pas encore qu'il photographie le bâtiment dans lequel ses propres photographies seront exposées quatre-vingt-trois ans plus tard. Ces plaques servent donc de documentation originale pour retracer l'histoire du bâtiment? qui accueille aujourd'hui non seulement le Musée de l'histoire de l'immigration,

S’il s'est par la suite spécialisé dans la photographie de culturisme en faisant poser

entre autres Arnold

Schwarzenegger devant son objectif, Arax photographie aussi le milieu artistique des Années folles. I' l'histoire de l'immigration ouvre ses portes sans collection préexistante. Trois collections, historique, ethnographique et artistique, sont alors créées pour être présentées au public à l'ouverture. Depuis, et suite à de nombreuses commissions d'acquisition, ces trois collections sont régulièrement enrichies. Ainsi, en 2009, le fonds Arax est acquis dans le but d'enrichir la collection iconographique et historique du musée et de pouvoir compléter notamment une des neuf sections ${ }^{8}$ du parcours permanent : "Ici et là-bas". Cette section aborde le maintien du lien avec le pays quitté. Au sein des familles et des groupes, on cherche souvent à recréer des ambiances, à perpétuer des traditions et coutumes pratiquées dans le pays d'origine, ou l'on tente tout simplement de recréer des lieux de "l'entre-soi". Ainsi, la deuxième série de plaques de verre traitant de la vie de la communauté arménienne en France entre 1920 et 1935, dont une grande part est consacrée aux activités sportives, est fort à propos.

\section{Le sport, un autre regard sur la vie associative arménienne}

En France, des années 1920 aux années 1950, le scoutisme est une activité très présente pour la jeunesse arménienne au même titre que pour les communautés russe et polonaise9, il sert à consolider la nation diasporique ${ }^{10}$. Krikor Djololian suit donc les camps de scouts arméniens, photographie leurs campements et activités sportives dans le milieu des années 1920. Peu de clichés sont pris sur le vif, il s'agit pour l'essentiel de groupes posant avec une banderole mentionnant la nation arménienne. Le photographe annote parfois ses photographies directement sur la plaque de verre, il y inscrit l'UGA (ou Homenetmen) avec les initiales en alphabet arménien, la section, la date et le lieu de la rencontre ou de l'événement. Plusieurs clichés sont pris à Paris, d'autres à Meudon, d'autres encore à Marseille. II signe ses plaques "Djololian" au début de sa carrière, puis "Arax" par la suite. Travailler avec des plaques de verre et non des négatifs films lui permet de les retoucher.

Arax photographie également les compétitions sportives, notamment d'athlétisme, et les remises de médailles organisées par les Arméniens eux-mêmes. Durant l'entre-deux-guerres, 
Krikor Djololian Arax, sportif à 20 ans (c) DJOLOLIAN

alors que la communauté arménienne pense encore à un éventuel retour, le sport est un moyen de résistance à la politique assimilationniste de la République". Dans ce contexte, Arax photographie les championnats et fait lui-même partie du comité d'organisation. Les plaques de verre, datées de 1925, suivent à peu de chose près le déroulé du programme de la grande fête sportive organisée par l'Union générale arménienne de culture physique et de scoutisme du 29 septembre (la mention de l'adresse du studio rue Papillon indique que nous sommes avant le début des années 1930) : cyclisme, saut en longueur, saut à la perche, course à pied...

Enfin, Arax photographie les bals et événements organisés par la communauté arménienne.
Le plus remarquable et le plus identifiable (puisqu'il l'a mentionné directement sur la plaque de verre) est le bal de coiffure arménien en 1935. Nombreuses encore sont les photographies de groupes, mais il y a aussi des portraits solo montrant des hommes en costume et des femmes en robe du soir.

S'il s'est par la suite spécialisé dans la photographie de culturisme en faisant poser entre autres Arnold Schwarzenegger devant son objectif, Arax photographie aussi le milieu artistique des Années folles. Ainsi, Mistinguett lui écrit une lettre en 1938 pour le remercier pour ses clichés. II immortalise les bals de Montparnasse, appelés "bals de la Horde", dont les protagonistes accordent leur tenue, aussi osée soit-elle, à la thématique de la soirée. On ne peut terminer sans mentionner ses reportages sur la Libération de Paris, dont le Musée Carnavalet, à Paris, détient une partie de la collection. Arax y prend des plans très rapprochés de Charles de Gaulle et de Winston Churchill, pour les plus emblématiques.

La photographie a un statut à part dans les collections d'un musée. Objets documentaires, témoignages ou œuvres artistiques, les images sont au cœur des questions liées aux représentations. L'œuvre du photographe Arax est à la fois une magnifique source pour l'histoire de l'immigration arménienne, et le regard d'un homme faisant lui-même partie de cette histoire.

Arax a-t-il voulu photographier la diaspora pour "faire mémoire" ? L'exploration de ce fonds photographique se poursuit. Elle révèlera sans doute d'autres éléments sur le dessein de son auteur et sur les pratiques sociales et culturelles d'une communauté en reconstruction en France. 